\title{
Effects of tobacco genetically modified to express protease inhibitor bovine spleen trypsin inhibitor on non-target soil organisms
}

\author{
Maureen O'CALLAGHAN ${ }^{1 *}$, Michael BROWNBRIDGE ${ }^{1,2}$, Wendy B. STILWELL', Emily M. GERARD ${ }^{1}$, \\ Elisabeth P.J. BURGESS ${ }^{3}$, Emma I. BARRACLOUGH ${ }^{3}$ and John T. CHRISTELLER ${ }^{4}$ \\ 1 Biocontrol, Biosecurity and Bioprocessing Section, AgResearch, Lincoln Research Centre, Private Bag 4749, Christchurch, New Zealand \\ 2 Previous address: University of Vermont, Entomology Research Lab, 661 Spear St, Burlington, VT 05405, USA \\ 3 HortResearch, Private Bag 92 169, Auckland, New Zealand \\ ${ }^{4}$ HortResearch, Private Bag 11 030, Palmerston North, New Zealand
}

\begin{abstract}
Effects of tobacco genetically modified to express the protease inhibitor bovine spleen trypsin inhibitor (BSTI) were examined in laboratory assays against three earthworm and one collembolan species. BSTI is a serine protease inhibitor that can bind to the digestive trypsins of insects feeding on modified plants, resulting in reduced growth and survival. Protease inhibitors are active against a broad range of insects, so may have a large impact on non-target organisms. Survival and fecundity of the collembolan Folsomia candida were unaffected by consumption of artificial diet containing BSTI-expressing tobacco leaf or powdered freeze-dried BSTI-expressing tobacco leaf that was added to soil. Similarly, mortality and growth of earthworms Aporrectodea caliginosa and Lumbricus rubellus did not differ significantly between soil augmented with BSTI-expressing tobacco leaves or unmodified control leaves. The redworm Eisenia fetida gained less weight when provided with BSTI-expressing leaves in one assay, but when the experiment was repeated, there was no significant difference between treatments. BSTI-expressing tobacco and unmodified control leaves decomposed at the same rate, indicating that the inhibitor had no effect on the overall function of the decomposer community of micro-flora and fauna in soil.
\end{abstract}

Keywords: environmental impacts / earthworms / protease inhibitor / GM plant / Collembola / decomposition

\section{INTRODUCTION}

Insect resistance is the second most commonly used trait, after herbicide resistance, in commercial genetically modified (GM) crops (James, 2005). Most insectresistant GM crops have been modified to express a variety of Bacillus thuringiensis (Bt) delta-endotoxins, but more recently plants expressing other insect-resistance proteins have been developed, including protease inhibitors (PIs), lectins and biotin-binding proteins (Ferry et al., 2004). Protease inhibitors bind to the active site of proteolytic enzymes, suppressing their catalytic activity (Laskowski and Kato, 1980). When expressed in plants, PIs can lower the activity of specific digestive proteases in susceptible insects feeding on the plants, causing a reduction in growth and survival (Gatehouse et al., 2000). Various plants have been modified to express PIs including sugarcane (Allsopp et al., 2000), white poplar

\footnotetext{
* Corresponding author:

maureen.ocallaghan@agresearch.co.nz
}

(Delledonne et al., 2001), and oilseed rape (de Leo et al., 2001).

Aprotinin, otherwise known as bovine pancreatic trypsin inhibitor (BPTI), is a serine PI of mammalian origin that has insecticidal properties when incorporated in artificial diet (Burgess et al., 1994; Markwick et al., 1998). Bovine spleen trypsin inhibitor (BSTI) is a BPTI homologue, and these two iso-inhibitors, which differ in eight amino acids of 59, have very similar binding properties against bovine trypsin (Fioretti et al., 1985). White clover expressing BSTI was shown to inhibit the growth of Wiseana sp. caterpillars (Voisey et al., 2001) and tobacco modified to express BSTI reduced growth and survival of Helicoverpa armigera larvae (Christeller et al., 2002).

Prior to the field release of insect-resistant GM plants, it is important to assess the effects on non-target organisms, particularly those that play a role in key ecosystem functions, to quantify potential risks/benefits associated with the uptake of this new technology. These "ecosystem service providers" include beneficial "above-ground" 


\section{O'Callaghan et al.}

species involved in pollination, predation, parasitism, etc., and those involved in maintaining the soil ecosystem. Collembola play a vital role in the removal, breakdown and recycling of crop residues, and are key indicators of soil fertility and health (Bitzer et al., 2002; Rebek et al., 2002). Collembola are often abundant in the rhizosphere, and in GM crops where the protein is expressed in all plant tissues they would be directly exposed to roots containing insecticidal proteins. Furthermore, as Collembola are principally involved in the decomposition of organic matter, they would be exposed to transgene-derived protein(s) remaining in crop residues. Because many species are too difficult to culture in the laboratory to provide sufficient numbers for bioassay purposes, Folsomia candida Willem is commonly used as a 'standard' test species (Fountain and Hopkin, 2005). It is parthenogenetic and easily reared, providing a ready source of genetically- and age-homogeneous insects. It has been used in several studies on non-target effects of GM plants (Romeis et al., 2003; Yu et al., 1997).

Earthworms also play a key role in soil ecosystem function through their contribution to nutrient cycling, impact on soil aeration and structure, and general stimulation of biological activity in soil. Many ingest soil and organic matter during feeding, or derive their nutrition from microbes associated with the breakdown of crop residues and in this way may be exposed to transgene-derived proteins. Earthworms such as Lumbricus terrestris L. (Annelida: Lumbricidae), L. rubellus (Hoffmeister) and Aporrectodea caliginosa (Savigny) have been used in several studies on non-target effects of GM plants including corn expressing Cry $3 \mathrm{Bbl}$ (Ahmad et al., 2006) and CrylAb (Saxena and Stotzky, 2001a; Vercesi et al., 2006; Zwahlen et al., 2003). Eisenia spp. have also been used as test species; Ahl Goy et al. (1995) found no effects of $B t$-expressing corn on mortality or weight gain of the epigeic (litter dwelling) species Eisenia fetida (Savigny).

While the non-target effects of Bt-plants have been well studied, fewer data are available for plants expressing other insecticidal proteins that could provide alternative pest control technologies and play an important role in resistance management strategies. Protease inhibitors have a wider range of activity than $B t$ proteins, binding to the digestive proteases of many insects (Terra and Ferreira, 1994). The similar binding domains of BPTI and BSTI (Fioretti et al., 1985) cause these inhibitors to bind more strongly to bovine digestive trypsin than any other known PI-protease interaction (Vincent and Lazdunski, 1972), suggesting that these inhibitors have greater potential for impacting non-target organisms that utilize proteases in their digestive systems than other insecticidal compounds with a similar mode of action. BSTI is therefore a good candidate for detection of any such impacts.

In the present paper we report on laboratory assays to evaluate effects of transgenic tobacco expressing BSTI on $F$. candida and three species of earthworm. In addition, the decomposition of BSTI-expressing tobacco was compared with unmodified tobacco leaves to provide a measure of impact on decomposing micro-flora and fauna in soil.

\section{RESULTS}

\section{Decomposition of BSTI-expressing leaves in soil}

The carbon contents of the two forms of leaf material differed significantly $(P<0.05)\left(0.382{\mathrm{~g} \mathrm{C} . \mathrm{g}^{-1}}^{-1}\right.$ leaf

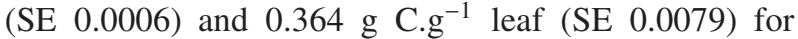
the BSTI-expressing tobacco and control tobacco respectively). Leaf nitrogen content was significantly greater $(P<0.05)$ for the control tobacco than the BSTI expressing tobacco $\left(0.050{\mathrm{~g} \mathrm{~N} . \mathrm{g}^{-1}}^{-}\right.$leaf (SE 0.00006) and

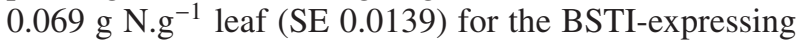
tobacco and control tobacco respectively). Consequently $\mathrm{C}: \mathrm{N}$ ratios of the BSTI-expressing tobacco differed significantly $(P<0.05)$ from the unmodified control tobacco (C:N $=7.65$ and 5.25 respectively).

The rate of $\mathrm{CO}_{2}$ evolution from the unamended soil was constant during the incubation period. Addition of tobacco leaves to soil significantly $(P<0.05)$ increased the rate of $\mathrm{CO}_{2}$ evolution from soil, with initial decomposition of the BSTI-expressing tobacco line and the unmodified parental line occurring at the same rate under laboratory conditions (Fig. 1). Decomposition of the tobacco leaves under the experimental conditions was rapid; after 42 days incubation, approximately $47 \%$ of tobacco leaf carbon had been converted to $\mathrm{CO}_{2}$.

\section{Collembola assays}

\section{Diet assays}

There was variation from week to week in the number of eggs produced per individual over the course of each assay (Tab. 1). There were no consistent trends across all sample times and both assays, suggesting that Collembola were not markedly affected by any of the treatments (tobacco, BSTI). Overall, egg production was highest across all treatments in weeks 1, 3 and 4 in Assay 1, and weeks 3, 5 and 7 in Assay 2. In Assay 1, egg production by yeast-fed individuals (control) was significantly higher than those fed on the tobacco diets $(P<0.05)$ (Tab. 1), but differences were not significant in Assay 2 (Tab. 1). The level of egg production declined across all 


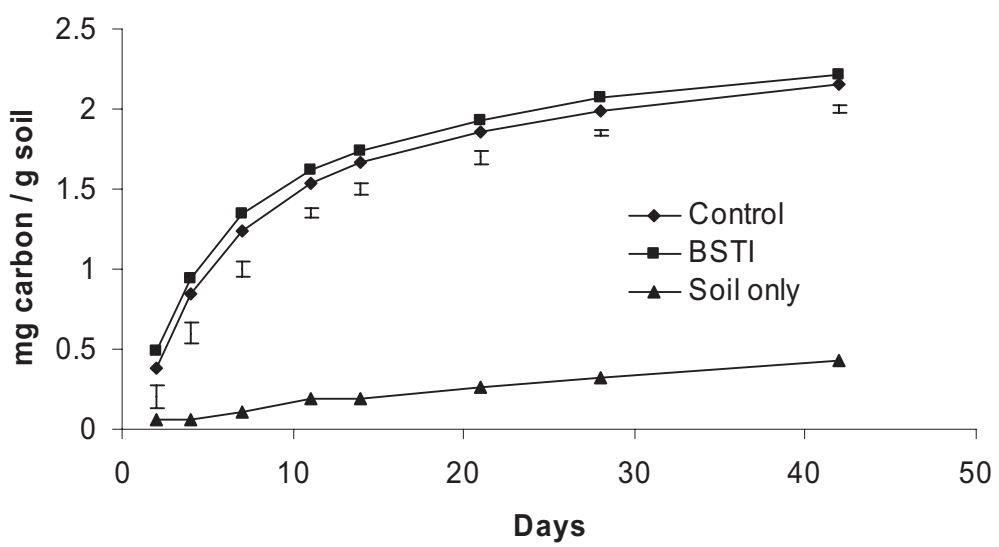

Figure 1. Mineralization of carbon in unamended soil and soil amended with leaf material from BSTI-expressing tobacco and unmodified parental control line leaf material. Each point is the mean of three replicates and the bars represent LSDs $(P<0.05)$.

treatments over time, but the rate of decline was not significantly different between treatments or assays.

Overall, in Assay 1, the difference in egg production by individuals fed on non-transgenic tobacco or transgenic tobacco was not significant (Tab. 1). In Assay 2, significantly more eggs were produced by Collembola fed on non-transgenic than transgenic tobacco diet $(P<$ 0.001). There was no effect of concentration in Assay 1, but significantly more eggs were produced by Collembola fed on diets containing $1.0 \%$ than $0.1 \%$ tobacco leaf powder (non-transgenic or transgenic) in Assay $2(P<0.001)$ (Tab. 1). Very few individuals died over the course of both experiments, and there was no significant effect of treatment on survival in either assay (Tab. 1).

\section{Soil assays}

Significantly higher populations of $F$. candida developed when fed on powdered yeast compared with either non-transgenic or BSTI-expressing tobacco powders $(P<0.01)$ (Tab. 2). This effect was consistent across both assays. There was no difference between populations fed on leaf powders from non-transgenic or BSTI-expressing tobacco (Tab. 2).

\section{Earthworm survival and development}

A. caliginosa did not survive well under the conditions in Trial 1. A. caliginosa provided with BSTI-expressing tobacco died between weeks 4 and 7, with all individuals dead by week 7 , while those provided with control leaves died between weeks 5 and 9, with only one earthworm remaining alive at week 9 . At week 9 mortality of $A$. caliginosa was significantly higher than for the other two earthworm species (15/16 A. caliginosa and 3/16 dead in each of E. fetida and L. rubellus; $\chi^{2}=15.37, P<0.001$ for comparing A. caliginosa with either E. fetida or L. rubellus). At week 9, no significant differences in mortality were observed between earthworms provided with the BSTI-expressing leaves and those receiving unmodified control tobacco leaves (8/8 and 7/8 dead in BSTI and control treatments for A. caliginosa, 2 and 1 E. fetida dead respectively, and 3 and 0 L. rubellus dead respectively; overall 13 and 8 dead in BSTI and control treatments respectively; $\chi^{2}$ for BSTI versus control leaves $=1.35$; NS). In Trial 2 , no mortality of $A$. caliginosa was observed in either treatment, while one individual $E$. fetida provided with control leaves died at week 3. Again, in Trial 2, there was no significant difference in mortality of earthworms provided with the BSTI-expressing leaves and those receiving unmodified control tobacco leaves.

In Trial 1, the change in average weight differed for each species of earthworm. E. fetida provided with unmodified control leaves showed an increase in weight of $77.5 \%$ but only a $42.5 \%$ increase when provided with BSTI-expressing leaves (Fig. 2) and the difference in relative growth rate was significant $(P<0.05$; Tab. 3$)$. As $A$. caliginosa failed to thrive under the conditions of the experiment (Fig. 3), no statistical analysis of weights was possible after 4 weeks but relative growth rates did not vary significantly between treatments. Similarly, leaf type had no significant effect on the relative growth rate of L. rubellus, which showed an average decrease in weight of $32.6 \%$ for both BSTI-expressing and unmodified control leaves (Tab. 3; Fig. 4).

In Trial 2, survival of $A$. caliginosa was improved at the lower temperature of $10-12{ }^{\circ} \mathrm{C}$ (Fig. 3). As seen in the previous experiment, earthworm weights were generally higher when this species was provided with BSTI-expressing leaves, and this was reflected in significantly different growth rates $(P<0.01$; Tab. 3). 


\section{O'Callaghan et al.}

Table 1. Mean number of eggs produced per individual per week (for 8 weeks) and survival (\%) of Folsomia candida following exposure to a $1 \%(\mathrm{w} / \mathrm{v})$ yeast-agar-based diet containing leaf powders derived from genetically modified tobacco expressing the bovine spleen trypsin inhibitor (BSTI) and its non-modified counterpart (T). There were two leaf powder concentrations $(0.1 \%$ and $1.0 \% \mathrm{w} / \mathrm{v})$. Two experimental assays (1 and 2) were carried out. In each experimental assay four replicate containers/treatment were set up with 10 individuals/replicate (total 40/treatment/assay). Egg production and survival were recorded in all containers (all treatments) each week.

\begin{tabular}{|c|c|c|c|c|c|c|c|c|c|c|}
\hline \multirow[b]{2}{*}{ Treatment } & \multicolumn{9}{|c|}{ Egg production/individual/week for weeks: } & \multirow{2}{*}{$\begin{array}{c}\text { Survival } \\
\text { at week } 8\end{array}$} \\
\hline & 1 & 2 & 3 & 4 & 5 & 6 & 7 & 8 & $1-8$ & \\
\hline \multicolumn{11}{|l|}{ Assay 1} \\
\hline Control $^{1}$ & 24.2 & 12.1 & 28.3 & 26.0 & 5.3 & 6.9 & 0.3 & 1.1 & 13.0 & 100.0 \\
\hline Т $0.1 \%$ & 16.5 & 13.3 & 15.5 & 7.2 & 1.6 & 0.7 & 0.2 & 0.1 & 6.9 & 97.5 \\
\hline Т $1.0 \%$ & 18.6 & 11.4 & 25.9 & 20.3 & 6.6 & 6.8 & 2.0 & 1.1 & 12.0 & 85.0 \\
\hline BSTI $0.1 \%$ & 24.1 & 7.5 & 18.8 & 15.6 & 1.0 & 0.7 & 0.3 & 0.1 & 8.8 & 85.0 \\
\hline BSTI $1.0 \%$ & 15.0 & 7.6 & 4.4 & 0.4 & 0.4 & 0.2 & 0.0 & 0.0 & 3.5 & 90.0 \\
\hline $\operatorname{LSD}(5 \%)$ & 11.8 & 10.3 & 12.8 & 13.5 & 4.5 & 3.5 & - & - & 4.9 & - \\
\hline \multicolumn{11}{|l|}{ Contrast $P$ values: } \\
\hline Control vs. Trtd & 0.206 & 0.573 & 0.023 & 0.009 & 0.098 & 0.002 & - & - & 0.012 & - \\
\hline $\mathrm{T}_{v s .} \mathrm{BSTI}^{2}$ & 0.610 & 0.178 & 0.050 & 0.208 & 0.039 & 0.013 & - & - & 0.058 & - \\
\hline $0.1 \%$ vs. $1.0 \%^{2}$ & 0.383 & 0.796 & 0.640 & 0.816 & 0.156 & 0.029 & - & - & 0.959 & - \\
\hline $2 \times 2$ interaction & 0.168 & 0.779 & 0.011 & 0.007 & 0.082 & 0.013 & - & - & 0.007 & - \\
\hline \multicolumn{11}{|l|}{ Assay 2} \\
\hline Control $^{1}$ & 7.7 & 9.9 & 22.7 & 8.8 & 10.8 & 4.3 & 12.9 & 7.0 & 10.6 & 94.4 \\
\hline Т $0.1 \%$ & 6.5 & 10.3 & 23.2 & 9.8 & 13.4 & 2.1 & 15.4 & 4.4 & 10.6 & 97.5 \\
\hline Т $1.0 \%$ & 6.8 & 9.1 & 28.7 & 9.6 & 15.2 & 6.1 & 16.6 & 5.0 & 12.2 & 100.0 \\
\hline BSTI $0.1 \%$ & 4.7 & 6.9 & 18.9 & 3.6 & 15.1 & 2.2 & 8.4 & 4.6 & 8.1 & 100.0 \\
\hline BSTI $1.0 \%$ & 5.4 & 20.2 & 27.5 & 10.0 & 11.0 & 5.4 & 8.6 & 2.6 & 11.3 & 100.0 \\
\hline $\operatorname{LSD}(5 \%)$ & 3.4 & 5.4 & 5.9 & 7.8 & 6.7 & 4.3 & 6.2 & 6.4 & 1.1 & - \\
\hline \multicolumn{11}{|l|}{ Contrast $P$ values: } \\
\hline Control vs. Trtd & 0.144 & 0.403 & 0.384 & 0.845 & 0.263 & 0.807 & 0.766 & 0.243 & 0.928 & - \\
\hline $\mathrm{T} v s . \mathrm{BSTI}^{2}$ & 0.181 & 0.048 & 0.180 & 0.270 & 0.561 & 0.830 & 0.003 & 0.594 & $<0.001$ & - \\
\hline $0.1 \%$ vs. $1.0 \%^{2}$ & 0.672 & 0.005 & 0.003 & 0.244 & 0.602 & 0.023 & 0.737 & 0.735 & $<0.001$ & - \\
\hline $2 \times 2$ interaction & 0.884 & 0.001 & 0.435 & 0.220 & 0.196 & 0.755 & 0.804 & 0.531 & 0.032 & - \\
\hline
\end{tabular}

${ }^{1}$ Control treatment $=$ yeast/agar diet only. ${ }^{2}$ Main effect contrasts.

With E. fetida, earthworms provided with both types of leaves increased in weight, with no significant differences between treatments (Fig. 2; Tab. 3).

\section{DISCUSSION}

Measurement of the rate of plant litter decomposition has been used as a measure of soil ecosystem function in previous studies on the effects of GM plants on non- target soil biota. Results of studies on decomposition of $B t$-plants are contradictory, with some studies reporting significant differences between $B t$-plants and unmodified plants (e.g. Flores et al., 2005), while other studies have found no detectable differences (Hopkins and Gregorich, 2003). Few studies have examined decomposition of other insect-resistant plants. The rates of decomposition of potato (Cowgill et al., 2002) and tobacco (Donegan et al., 1997) expressing a PI were found to be comparable to non-GM plants, as measured by weight 

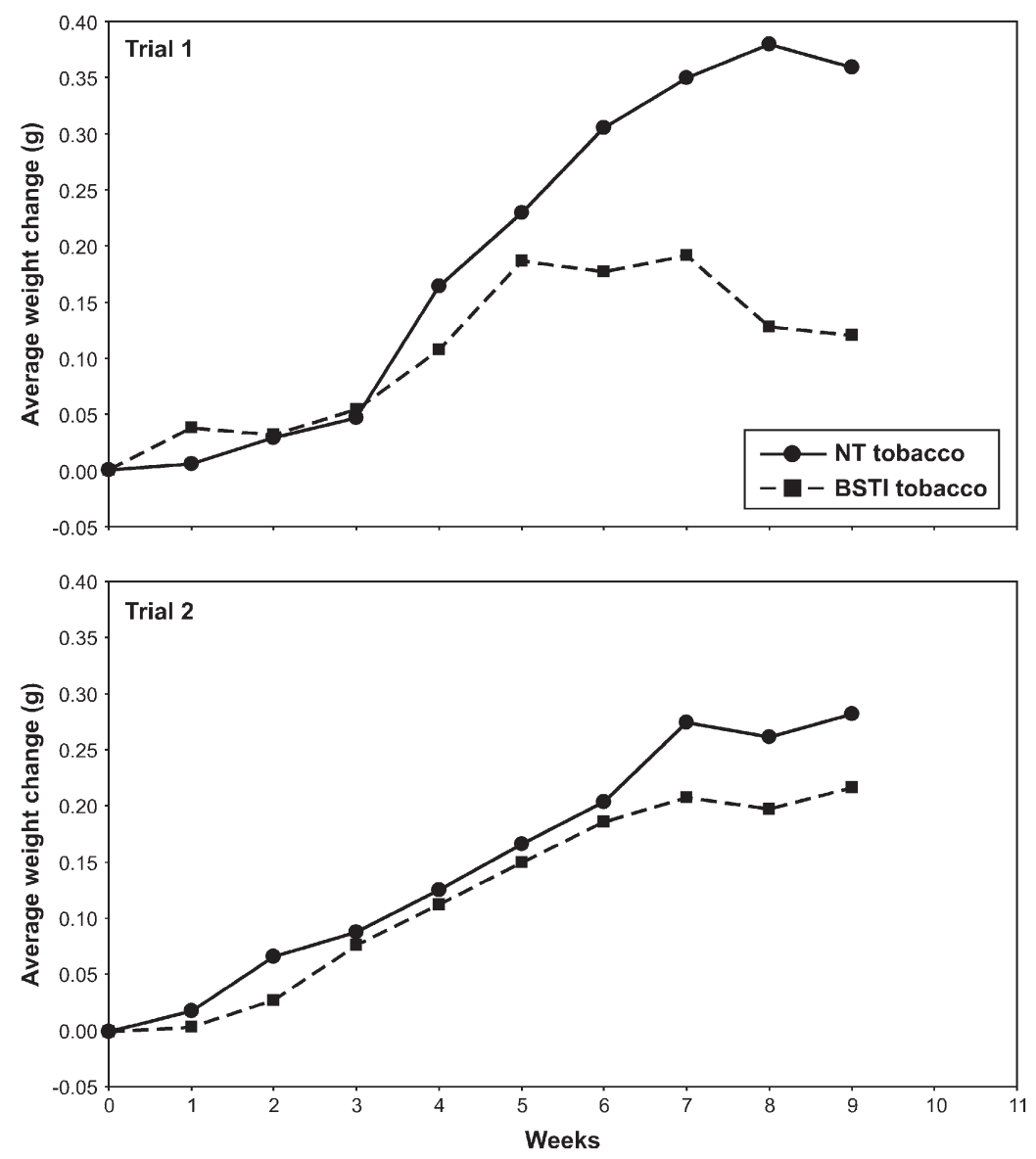

Figure 2. Average weight change of Eisenia fetida provided with BSTI-expressing tobacco leaves or unmodified control leaves in two laboratory assays. Trial $1, \mathrm{n}=8$; Trial $2, \mathrm{n}=10$.

Table 2. Mean number of Folsomia candida extracted from soil assay cups $(n=6)$ after 8 weeks of feeding on powdered yeast (Control), or freeze-dried tobacco leaf powders from non-transgenic (NT) or bovine spleen trypsin inhibitor (BSTI)-expressing plants. Values are square root means with back-transformed means given in parentheses. Two experimental assays (1 and 2) were carried out.

\begin{tabular}{lcc}
\hline \hline Treatment & Assay 1 & Assay 2 \\
\hline Control & $33.0(1089)$ & $32.4(1050)$ \\
NT tobacco & $17.0(289)$ & $18.7(350)$ \\
BSTI tobacco & $19.2(369)$ & $21.5(462)$ \\
& & \\
LSD (5\%) & 4.2 & 4.5 \\
Contrast $P$ values: & & 0.005 \\
Treated versus Control & 0.003 & 0.112 \\
NT versus BSTI & 0.157 & \\
\hline
\end{tabular}

loss in litterbag studies. In the current study, short term decomposition of ground BSTI-expressing leaves did not differ significantly from unmodified control leaves under the conditions used in the experiment $\left(20{ }^{\circ} \mathrm{C} ; 25 \%\right.$ soil moisture).

There was no consistent effect of BSTI-expressing tobacco on any of the life history parameters of $F$. candida measured in this study. Differences observed in the first diet assay and the halt in egg production by week 6 may have been largely attributable to the aging $F$. candida culture and an associated reduction in fecundity, especially as this occurred across all treatments and did not occur in the second assay (Fountain and Hopkin, 2005).

Distinct ovipositional peaks occurred in each assay and continued in a downward trend over time. When studying the life-history of F. candida in the laboratory, Snider (1973) found that oviposition generally began within 48 hours of ecdysis and only occurred during alternate instars. Consequently, peaks in egg production will vary according to the age and stage of development of the 
M. O'Callaghan et al.
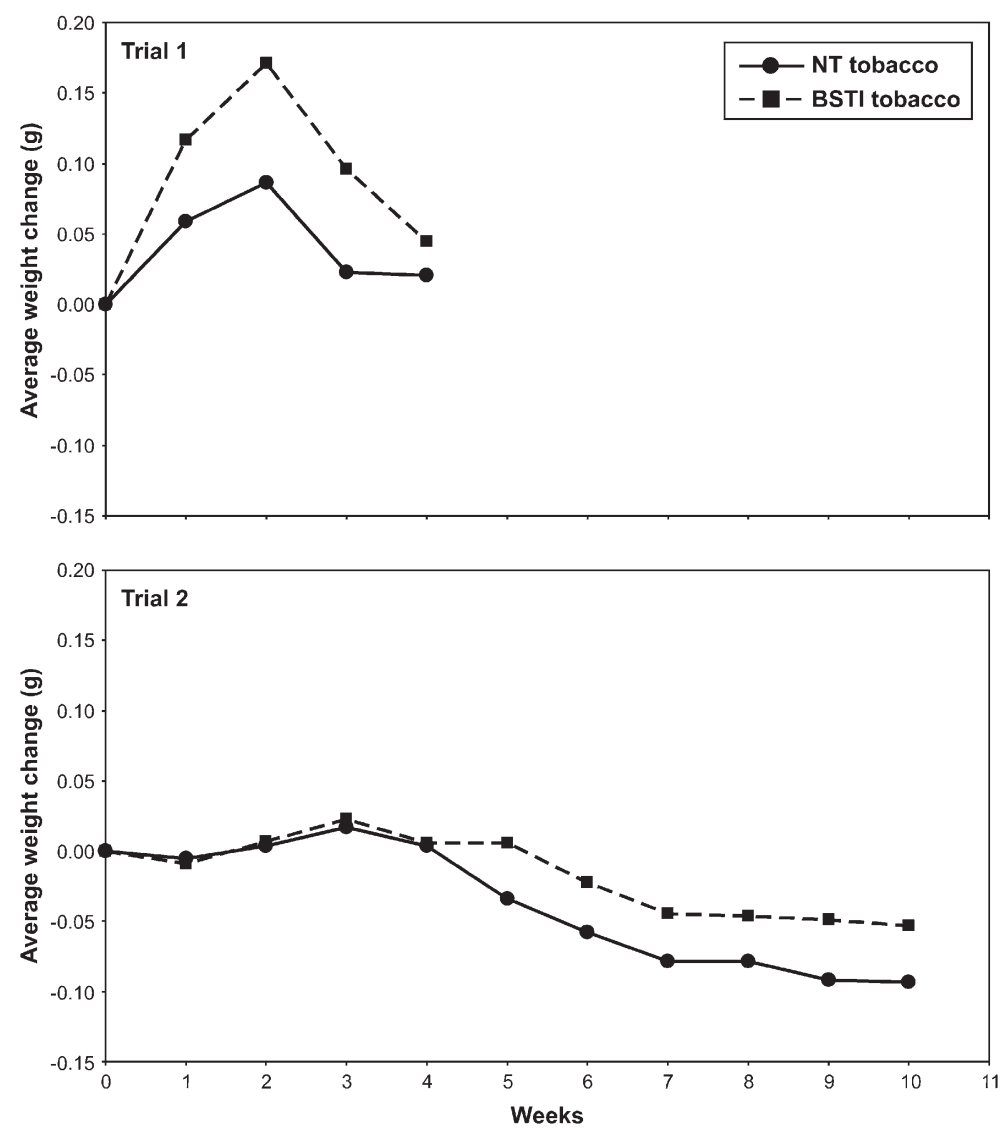

Figure 3. Average weight change of Aporrectodea caliginosa provided with BSTI-expressing tobacco leaves or unmodified control leaves in two laboratory assays. Trial $1, \mathrm{n}=8$; Trial $2, \mathrm{n}=10$.

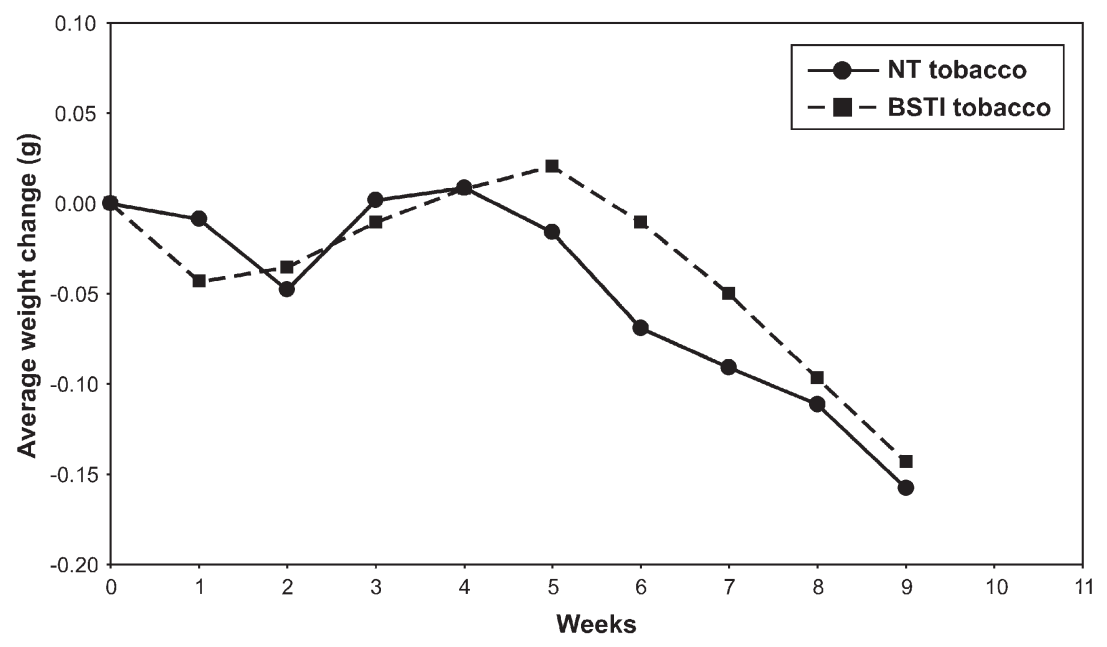

Figure 4. Average weight change of Lumbricus rubellus provided with BSTI-expressing tobacco leaves or unmodified control leaves $(\mathrm{n}=8)$. 
Table 3. Relative growth rates (per week; defined in Materials and Methods section) for three species of earthworm provided with fresh leaf material from non-transgenic (NT) or bovine spleen trypsin inhibitor (BSTI)-expressing tobacco plants in two trials (Trial 1, $\mathrm{n}=8$; Trial 2, $\mathrm{n}=10)$.

\begin{tabular}{|c|c|c|c|c|c|}
\hline \multirow{3}{*}{ Treatment } & \multicolumn{3}{|c|}{ Trial 1} & \multirow{2}{*}{\multicolumn{2}{|c|}{$\begin{array}{c}\text { Trial } 2 \\
\text { Wks 0-10 }\end{array}$}} \\
\hline & \multirow{2}{*}{$\frac{\text { Wks } 0-4}{\text { A. caliginosa }}$} & \multicolumn{2}{|c|}{ Wks 0-9 } & & \\
\hline & & E. fetida & L. rubellus & A. caliginosa & E. fetida \\
\hline NT tobacco & 0.001 & 0.099 & -0.042 & -0.047 & 0.084 \\
\hline BSTI tobacco & 0.010 & 0.039 & -0.028 & -0.026 & 0.072 \\
\hline $\operatorname{LSD}(5 \%)$ & 0.063 & 0.045 & 0.029 & 0.014 & 0.086 \\
\hline$P$ value & 0.768 & 0.013 & 0.323 & 0.009 & 0.747 \\
\hline
\end{tabular}

individuals used to initiate the experiment. While every effort was made to standardize the age of the Collembola used in the study, and individuals from the same cohort were used in all treatments in each assay, the age of individuals could have varied by 3-4 days within each replicate, and by up to 10 days between assays. This could have accounted for the slight difference in the timing of egg laying events between replicates. The duration between ovipositional successions is 11-13 days (Snider, 1973), so that one or more non-reproductive stages could have occurred between observations, and would further contribute to differences in the timing of the peaks within and between assays. Duration between instars lengthens as the organisms mature, thus the peaks observed in the current study may be directly correlated with the age of the individuals used to establish the experiment, and the timing of adult reproductive and ovipositional bouts.

Fecundity in Collembola is directly correlated with the nutritional quality of their diet, the amount of food available, and feeding preferences; less favorable diets or limited food supply can compromise progeny levels (Stam et al., 1996). Examining effects of various diets and their nutritional quality on the life history of three F. candida clones, Stam et al. (1996) showed that F. candida developed faster, reached reproductive maturity earlier, and produced more offspring on yeast than the other diets. In the current study, diet (yeast-agar or powdered tobacco leaf) had no apparent effect on reproduction and survival in $F$. candida, as differences in egg production over 8 weeks were not significant, although egg production declined earlier in cultures fed on the BSTI-diet. Effects of the nutritional value of the diets, or the presence of BSTI, were thus too small to result in significant differences in measures of this life-history trait. Moreover, the levels of BSTI presented to F. candida were far higher than would be anticipated under field conditions, so it is unlikely that there would be a major impact on natural collembolan populations if this technology was utilized.
F. candida survival was unaffected by treatment in both assays. A direct toxic effect would be manifested by increased mortality in the treated population so that within the defined parameters of the current trial, BSTI had no measurable effect on collembolan longevity. While chronic effects may be detected by extending the experimental period, on the basis of the present trial, BSTI does not appear to pose a major risk.

It was clear from the soil assays, that yeast was a more suitable food for $F$. candida, resulting in the higher populations developing in the control treatments compared with those fed on either of the tobacco leaf diets. Thus, the nutritional quality of the insect's diet and associated indirect effects of GM crops may play more significant roles in population development than the presence/absence of BSTI; similar findings have been obtained in Bt-transgenic crops (Ashouri et al., 2001; Clark and Coats, 2006). Food quality has a direct influence on collembolan health and fecundity and Snider (1973) determined that $F$. candida readily consume or absorb their eggs when they have insufficient food. Our findings are consistent with those of van Amelsvoort and Usher (1989) and Romeis et al. (2003), who showed that F. candida mature earlier on an optimal yeast diet compared with one comprised of plant material. The soil assay findings essentially confirm observations in the diet trial. As in the diet trials, the amount of tobacco leaf powder (and consequently the amount of BSTI) presented to F. candida was considerably higher than would be encountered under natural conditions. Furthermore, diet was added to each container on a weekly basis, so that elevated levels were maintained in the soil for the duration of the trial. Although $F$. candida is not commonly found in agricultural soils, it is widely used in ecotoxicological studies due to the ease of its mass-rearing and the genetic homogeneity of cohorts. Thus, while it cannot be used to directly predict responses of field populations of Collembola, it serves as a good test species for detection of gross toxic or other potential side-effects of a specific treatment 


\section{O'Callaghan et al.}

or practice. The lack of a specific response by $F$. candida to BSTI in the current study suggests that the direct risks associated with this technology are low. However, there may be some indirect influences if the microbial decomposer community that is able to utilize transgenic plant parts was affected (Flores et al., 2005; Saxena and Stotzky, 2001b) with subsequent impacts on Collembola, which feed on detritus and microorganisms associated with the breakdown of organic matter (Berg et al., 2004).

Both E. fetida and A. caliginosa have been used in ecotoxicological testing, where they represent different ecological strategies (Kula and Larink, 1998). E. fetida is epigeic while A. caliginosa is a horizontally burrowing mineral soil species (endogeic). Of these two species, E. fetida is the preferred test species because of difficulties in maintaining A. caliginosa for long periods under experimental conditions. In the present study, experimental conditions for A. caliginosa were less than optimal although good survival was achieved in the second experiment. This species is also a very selective feeder, ingesting fungi, bacteria and algae. Given its feeding habits, it is unlikely that A. caliginosa would have been feeding directly on the plant material added to pots, so direct effects of BSTI were not expected. E. fetida gained in weight during the experiment and is known to feed on plant litter. This species was more likely to show an impact of BSTI, and while mortality did not differ between treatments, E. fetida individuals gained more weight when provided with unmodified control leaves in the first experiment, but this trend was not observed in the second experiment.

To date, studies on the effects of GM plants on earthworms have been limited to $B t$-plants with assays using L. terrestris (Ahmad et al., 2006; Saxena and Stotzky, 2001a; Zwahlen et al., 2003), E. fetida (Ahl Goy et al., 1995) and A. caliginosa (Vercesi et al., 2006). In general, studies have reported few adverse effects on mortality, growth or reproduction. Vercesi et al. (2006) reported a slight but statistically significant negative effect of $B t$-corn residues on the hatchability of A. calignosa cocoons, with hatching success reduced from about 95 to $75 \%$ in a treatment receiving the highest concentrations of corn litter. Zwahlen et al. (2003) reported lower weight gains by juvenile $L$. terrestris provided with Bt-corn litter than control litter; this difference became apparent after 200 days, and prior to this there was no difference between treatments. They concluded that further work was necessary before this difference in relative weight could be attributed to the $B t$ protein or other factors such as the nutritional quality of the plant material ingested by the earthworms. As discussed above, several studies have found that GM and unmodified plant lines can vary in characteristics such as $\mathrm{C}: \mathrm{N}$ ratio and lignin content, which could affect growth and development of test species. In the current study C:N ratios varied slightly between BSTI-expressing and non-modified tobacco. This difference was unlikely to have been caused by growing conditions, as plants were grown in the same medium under uniform management conditions and plants were all the same age.

There is currently no method available to monitor the fate of BSTI in soil, as can be done with Bt protein (e.g. Hopkins and Gregorich, 2003; Zwahlen et al., 2003). For this reason, weekly additions of the plant material were made to soil to maintain the level of BSTI in the soil in the earthworm experiments. Based on amounts of leaf material added and measured expression levels, it is estimated that soil contained between 500-700 ng BSTI. ${ }^{-1}$ soil. This level is similar to amounts of $B t$ protein estimated to be present in pot trials studying impacts of $B t$-plants which, based on known expression levels and amounts of leaf material used, has been estimated at 200-700 ng $B t . \mathrm{g}^{-1}$ soil, with $B t$ levels in field soils reported to be at least an order of magnitude lower than in pot experiments (Christeller et al., 2006). Attempts to increase the amount of BSTI in soil by addition of dried tobacco powder to soil containing earthworms were unsuccessful, as earthworms failed to thrive, probably because of the increased concentration of other compounds present in tobacco that are detrimental to earthworm development and survival (Chari et al., 1992; El-Gayar et al., 1975). In both the artificial diet and soil assay, F. candida was exposed to significantly higher levels of BSTI than would be encountered under natural conditions.

While it was not possible to monitor the level of BSTI in soil, residual activity of BSTI has been determined in the bodies and frass of Spodoptera litura larvae following feeding of larvae on transgenic tobacco plants. Christeller et al. (2005) showed that the trypsin-binding ability of BSTI in the larvae was reduced by half, and in frass BSTI had lost about $90 \%$ of its ability to bind trypsin. It would be interesting to monitor the residual activity of BSTI following passage through earthworms, to determine if recombinant proteins such as BSTI could be dispersed in sufficient quantities to cause non-target effects beyond the transgenic crop.

BSTI has been found to be an effective inhibitor of pest species in transgenic plants (Christeller et al., 2002) but its impacts on non-target organisms studied to date (carabid beetle: Burgess et al. (2002) and adult honey bee: Malone et al. (2004)) have been minimal. To impact on non-target species, BSTI must be stable in the digestive system. Little is known about the digestive systems of earthworms, but data from an early study (Bewley and DeVillez, 1968) suggested that earthworms produce trypsins as part of their gut proteolytic cocktail.

The inability of BSTI to interfere with growth of non-target organisms has many possible interpretations, 
e.g. failure of the inhibitor to bind, excess of protease over inhibitor, the lack of importance of trypsin to protein digestion, degradation of the inhibitor by other proteases, the involvement of compensatory mechanisms and the non-rate-limiting role of protein in earthworm growth. Only in the first situation would we expect to observe free inhibitor in earthworm casts. Further work is required to determine why BSTI is ineffective. The same set of considerations applies to Collembola.

In summary, at rates comparable to those used in impacts studies on $B t$ toxins, BSTI had no effect on mortality and growth of three earthworm species, and exposure of the collembolan Folsomia candida to significantly higher rates had no effect on development and fecundity. Similarly there was no detectable effect of BSTIexpressing tobacco on soil function, as determined by measuring the decomposition rate of tobacco leaves in soil. Given these findings, it is unlikely that negative impacts would occur in the field. However, it is prudent to consider additional studies to confirm that there are minimal ecological risks associated with this novel crop protection technology. Experiments with juvenile earthworms will be carried out, as their susceptibility may be higher than susceptibility of adult earthworms used in the current experiments. Data from the current experiments will be used to determine the level of replication required for more stringent analysis of effects on juvenile earthworms. In addition, longer-term trials and choice tests for both earthworms and Collembola will enable effects of BSTI on reproduction and habitat preferences to be determined, and tests using collembolan species native to New Zealand would be desirable. Ultimately, however, comparisons between this pest management technology and conventional (i.e. pesticide-based) management are needed to assess the benefits and risks associated with each crop protection system. Comparative data of this kind are needed to aid decision-makers and regulators when considering applications for registration of new agricultural biotechnologies.

\section{MATERIALS AND METHODS}

Experiments on decomposition and the effects of BSTIexpressing transgenic tobacco on earthworms were conducted at AgResearch, Lincoln, New Zealand. Bioassays examining the effect of the same lines of transgenic tobacco on survival and fecundity of Collembola were carried out at the Entomology Research Laboratory, University of Vermont, USA.

\section{Plant material}

Tobacco (Nicotiana tabacum L. cv. Samsun) plants transformed using a standard Agrobacterium tumefaciens- mediated protocol to express BSTI (Christeller et al., 2002) were grown in a containment glasshouse at 20$25{ }^{\circ} \mathrm{C}$ in pots containing a bark-based potting mix with fertilizers. Seeds used were the third generation of successive self-fertilizations of high-expressing offspring from two plants derived from separate transformation events, and represented lines BSTI T $\# 6$ and BSTI $\mathrm{T}_{3} \# 12$. Levels of BSTI expressed in leaves were determined for each plant 2-3 months after sowing, using the methods described previously (Christeller et al., 2002). Only plants expressing high levels of BSTI were used in the present experiments. Plants used in the Collembola bioassays had a mean expression level of $47.1( \pm 1.8) \mathrm{ng}$ BSTI. $\mathrm{mg}^{-1}$ fresh weight leaf (mean $( \pm$ SE)). In earthworm Trial 1, plants had a mean expression level of 19.4 ( \pm 0.35) ng BSTI.mg ${ }^{-1}$ leaf, and for earthworm Trial 2 and the decomposition study, plants used contained $22.4( \pm 0.40) \mathrm{ng}$.

BSTI is expressed from the $35 \mathrm{~S}-\mathrm{CaMV}$ promoter, which is constitutive and expresses throughout the plant. Expression is proportional to protein concentration in the tissues, being about 10-fold higher in the leaves than in the stem or root, so leaves were selected for use in experiments, to ensure that test organisms were exposed to reasonable levels of BSTI. Leaves chosen were young and fully expanded, approximately $25-40 \mathrm{~cm}$ long, being the 3 rd to 6 th leaves from the top of the plant (of leaves over $10 \mathrm{~cm}$ long). Leaves used in bioassays with Collembola had their midribs removed using a scalpel, were frozen at $-20{ }^{\circ} \mathrm{C}$ within 1 hour of harvesting, freeze-dried for at least 48 hours, then vacuum packed. There was no loss of BSTI activity following freeze-drying, which reduced the leaves to $11.7 \pm 0.41 \%$ of their fresh weight. Leaves used in earthworm experiments were collected, stored fresh at $5{ }^{\circ} \mathrm{C}$ and used in experiments within 3 days of harvest. Leaves from 20-30 BSTI-expressing plants and unmodified control plants were chopped to give leaf sections approximately $1 \times 1 \mathrm{~cm}$ in size. Leaves used in the decomposition experiment were dried at $40{ }^{\circ} \mathrm{C}$ and ground with a mortar and pestle before use.

\section{Soil}

Soil (Wakanui silt loam classified as Greywackie alluvium with some loess) used for the decomposition and earthworm experiments was collected from 2-15 cm depth beneath pasture on the AgResearch Lincoln farm. Soil had a $\mathrm{pH}$ of 6 , contained $5.9 \%(\mathrm{w} / \mathrm{w})$ organic matter, $0.31 \%$ nitrogen, $3.86 \%$ carbon, and had a $\mathrm{C}: \mathrm{N}$ ratio of 12.60. The soil was sieved to pass through a $2 \mathrm{~mm}$ sieve and pre-incubated at $20{ }^{\circ} \mathrm{C}$ for 7 days at $25 \%$ (w/w) soil moisture content ( $30 \%$ soil moisture is field capacity).

The soil used in Collembola assays was collected from a field adjacent to the University of Vermont 


\section{O'Callaghan et al.}

Entomology Research Laboratory. The soil belongs to the Windsor series, which are characteristically deep, poorly graded, and excessively drained loamy sands, and are classified as mixed, mesic Typic Udipsamments. Prior to use in assays, the soil was sieved to remove stones and other larger particulate matter, and autoclaved for $60 \mathrm{~min}$ utes.

\section{Decomposition of BSTI-expressing tobacco in soil}

Air-dried plant material ( $0.4 \mathrm{~g}$ of leaf) was mixed with the equivalent of $40 \mathrm{~g}$ dry weight soil in plastic vials and the mixture incubated at $20^{\circ} \mathrm{C}$ in Mason jars (gas tight lids) with a vial containing $3 \mathrm{~mL}$ of $2 \mathrm{M}$ potassium hydroxide $(\mathrm{KOH})$ and $10 \mathrm{~mL}$ of water in the bottom of the jar to maintain humidity. Soil moisture content was maintained at $25 \%(\mathrm{w} / \mathrm{w})$ throughout the experiment. Carbon mineralized was estimated at regular intervals by measuring the amount of $\mathrm{CO}_{2}$ absorbed in the $\mathrm{KOH}$ solution by titrating against $0.5 \mathrm{M}$ hydrochloric acid after addition of $1 \mathrm{~mL}$ of $1.5 \mathrm{M}$ barium chloride and 3 drops of $1 \%$ phenolphthalein. Water lost from the soil was periodically replaced as measured through mass loss, and $\mathrm{KOH}$ traps were replaced regularly. The decomposition experiment was conducted in triplicate, with three jars containing no soil, three with soil but no added plant material and three each amended with leaf residues from BSTI-expressing tobacco or the unmodified parental control line plant material. The total $\mathrm{C}$ and $\mathrm{N}$ contents were determined using a Leco CNS-2000 elemental analyzer (Lincoln University).

\section{Collembola assays}

\section{Test species}

Folsomia candida (Willem) originated from Mt. Fuji, Japan, and were cultured in glass jars $(7 \mathrm{~cm}$ height $\times 6 \mathrm{~cm}$ diameter) with a plaster-of-Paris/charcoal mixture $(9: 1)$ in the base to a depth of $1.5 \mathrm{~cm}$. The plaster mixture was moistened weekly with sterile distilled water (SDW) to maintain high internal ambient humidity, and jars were closed using plastic food wrap (Network ${ }^{\circledR}$ Chicago, Illinois). Cultures were fed weekly on diet blocks $(\sim 5.5 \mathrm{~mm})$ consisting of Fleischmann's active dry yeast (Burn Philip Food Inc., Fenton, MO) and Difco ${ }^{\circledR}$ Agar (Becton Dickinson and Company, Sparks, MD) $(10 \%$ yeast $\mathrm{w} / \mathrm{v})$. Any remaining old diet was removed prior to the addition of new food to reduce the build-up of contaminants. Colonies were held in an incubator at $20.4{ }^{\circ} \mathrm{C}$.

Age-homogenous colonies were achieved by adding sexually mature adults ( $\sim 100$ individuals) to a new culture jar, which had been previously surface-sterilized by placing under UV light for 20 minutes, and providing them with fresh diet for 2 days. After 2 days, adults were removed using an aspirator along with the diet blocks. The plaster-of-Paris was moistened weekly, and jars were held at $20.4{ }^{\circ} \mathrm{C}$. Eggs hatched in 10-12 days, and Collembola were fed and maintained as described above. For all assays, sexually mature $F$. candida ( $\sim 6$ weeks old) were used. As this species is parthenogenetic and males are not produced within a population, all individuals used were females.

\section{Incorporation of tobacco-leaf powders into Collembola diet}

Two separate diet assays were carried out using tobacco leaf powders (non-transgenic and BSTI-expressing), which were incorporated into a $1 \%(\mathrm{w} / \mathrm{v})$ yeast-agar diet at 0.1 and $1.0 \% \mathrm{w} / \mathrm{v}$ concentrations. Controls were fed on yeast-agar diet only. Test concentrations were pre-mixed with $1 \mathrm{~mL}$ SDW prior to incorporation into a molten yeast-agar diet cooled to $50{ }^{\circ} \mathrm{C}$. After mixing, the diet was poured into sterile plastic Petri dishes $(5.5 \mathrm{~cm}$ diameter $)$, which were quickly transferred to a refrigerator $\left(4{ }^{\circ} \mathrm{C}\right)$ to solidify. When cool, blocks of the diet were presented to the test insects in small plastic assay cups. These contained a thin layer of plaster of Paris plus activated charcoal, which was moistened throughout the experiment, providing an ideal environment for collembolan survival and reproduction. The diet blocks were replaced every 2-3 days (3 times per week) over the experimental period. Ten mature Folsomia were placed in each cup, and 4 replicates were set up. The design for each of the two assays was a randomized complete block, with 4 blocks of 5 treatments, the latter forming a $2 \times 2$ factorial +1 (control), with factors leaf powder (non-transgenic and BSTI-expressing) and concentration ( 0.1 and $1.0 \%)$. The Collembola were presented with treated diet exclusively for 4 weeks, after which survivors were fed for a further 4 weeks on yeast-agar only diet. Eggs were removed and counted every 7 days, and the number of survivors recorded. Any cadavers were removed at the same time.

\section{Soil assays}

Effects of the tobacco powders were also assessed in two separate soil assays. The soil used in each experiment was collected from a field adjacent to the University of Vermont Entomology Research Laboratory and is classified as belonging to the Windsor series, which are characteristically deep, poorly graded, and excessively drained loamy sands. Prior to use, the soil was sieved to remove stones and other larger particulate matter, and autoclaved for 60 minutes.

Soil assays were carried out using $1 \mathrm{oz}$. plastic portion cups $(4.5 \mathrm{~cm}$ height $\times 4.2 \mathrm{~cm}$ depth) (Fill-Rite Corp., 
Newark, NJ). Drainage holes were made in the base of the cups prior to lining with a plaster-of-Paris/charcoal mixture (9:1) (about $0.5 \mathrm{~cm}$ deep). The plaster-of-Paris was allowed to harden overnight prior to placing under UV light for 30 minutes to sterilize the surface before use. After UV sterilization, SDW was added to the plaster-ofParis to the point of saturation. This maintained high humidity in the soil environment even as it dried, enhancing collembolan survival. Sterile soil was moistened (35\% by weight) with SDW and added to each assay container (about $20 \mathrm{~g}$ per container), taking care not to compact the soil within the cups. Five 6-week old $F$. candida were added to each of the soil assay containers prior to application of the different diets.

Three treatments were tested, each represented by six replicate assay containers: (1) dried ground baker's yeast (optimal diet), (2) freeze-dried, non-transgenic tobacco leaf powder and (3) freeze-dried BSTI-expressing tobacco leaf powder. Cups were held at $20{ }^{\circ} \mathrm{C}$. Approximately $0.005-0.010 \mathrm{~g}$ of each diet was sprinkled onto the surface of the soil weekly. The soil was re-moistened on the same day, prior to the addition of the diet, by adding approximately $2.5 \mathrm{~mL}$ SDW to the surface of the soil using a dropper pipette, taking care not to saturate the medium. Assay containers were covered with plastic food wrap. The 18 containers were arranged as 9 pairs in a $3 \times 3$ Latin square design, physically forming a $6 \times 3$ arrangement on a plastic tray. Cups were maintained in the dark in a controlled-temperature incubator at $20.4{ }^{\circ} \mathrm{C}$ for 8 weeks, after which soil populations were extracted by flotation.

After 8 weeks, soils from each assay cup were emptied into $250 \mathrm{~mL}$ beakers and $100-150 \mathrm{~mL}$ SDW was added to each beaker. The contents were then gently mixed with a glass stir rod. Collembola in the soil floated to the surface. Beakers were left to stand for about 15 minutes, allowing the soil to settle. F. candida could then be separated from the soil by pouring the supernatant into a Buchner funnel $(5.5 \mathrm{~cm}$ diameter) lined with Whatman \#1 filter paper. Remaining water was gently drawn off under vacuum, leaving the Collembola on the surface of the filter paper. The Collembola were killed by spraying with $75 \%$ ethyl alcohol. Filter papers were then removed and placed in Petri dishes with a few drops of SDW to prevent desiccation. The total number of $F$. candida individuals recovered from each assay container was then counted. No attempt was made to differentiate populations based on developmental stage, and eggs were not included in the count. This was repeated for all treatments and replications.

\section{Earthworm assays}

Test species

Three earthworm species were used in experiments:
(1) Aporrectodea caliginosa Savigny (Annelida: Lumbricidae) is a common earthworm species in New Zealand pastures. Found at depths of $15-30 \mathrm{~cm}$ in soil, this species breaks down the root-mat under topsoil, contributing to nutrient cycling and productivity of pasture soils. A. caliginosa used in assays were collected from the AgResearch Lincoln farm. As A. caliginosa were field collected, it was not possible to ensure a single cohort was used but all individuals would have hatched from over-wintering eggs, at approximately the same time in spring as soil temperatures increased. Individuals of similar size were selected and randomly allocated across treatments. Before use, earthworms were held in pots containing the soil used in the trials at 10 $15^{\circ} \mathrm{C}$ for approximately 1 week.

(2) Eisenia fetida Savigny (Annelida: Lumbricidae) is a litter dwelling species found in the top $5 \mathrm{~cm}$ of soil and consumes large amounts of highly concentrated organic matter such as compost and manure. E. fetida were purchased from Bedrock Worms, Lyttleton, Canterbury. Earthworms are reared continuously and individuals were raised from batches of eggs recovered on the same day, providing a test population that was of relatively ( \pm 7 days) even-aged. Worms were also presorted by size and then randomly assigned to the respective treatments.

(3) Lumbricus rubellus Hoffmeister (Annelida: Lumbricidae) also lives in the top $5 \mathrm{~cm}$ of soil where it consumes manure lying on top of pastures but it can also live in compost. Adults were collected from beneath cowpats on dairy pasture at the Lincoln University dairy farm, Lincoln, Canterbury. As with the other earthworm species tested, L. rubellus were pre-sorted and individuals of similar size were randomly allocated across treatments.

\section{Pot assays}

Soil (300 g dry weight) was weighed into plastic pots (85 $\mathrm{mm}$ diameter, $100 \mathrm{~mm}$ height) and sufficient water was added to give $25 \%$ soil moisture content, which was maintained for the duration of the experiment. Fresh, shredded tobacco leaves $(8 \mathrm{~g})$ were mixed into the soil in each pot, either transgenic tobacco leaves expressing BSTI or unmodified tobacco leaves. Individual worms were added to each pot. The three earthworm species described above were used, with eight replicates for each type of worm feeding on each type of litter. Worms were weighed before addition to pots. The total weight of the soil + pot was recorded and the lids were punctured to allow air flow. The pots were incubated in a controlled temperature room $\left(15-17^{\circ} \mathrm{C}\right)$. Worms were weighed and pots supplemented with an additional $8 \mathrm{~g}$ plant material each week for 9 weeks.

A second earthworm experiment was carried out using A. caliginosa and E. fetida(10 replicates of each 


\section{O'Callaghan et al.}

species). In this experiment, earthworms were provided with $10 \mathrm{~g}$ plant material each week and pots were incubated at $10-12{ }^{\circ} \mathrm{C}$ to improve earthworm survival.

\section{Statistical analysis}

For the soil assays, $F$. candida counts were square-root transformed prior to analysis of variance. For each earthworm, the relative growth rate (RGR) was calculated as the slope of the regression line of $\log _{\mathrm{e}}$ (weight, $W$ ) against time in weeks $(t)$

$$
\mathrm{RGR}=\frac{\mathrm{d}\left(\log _{\mathrm{e}} W\right)}{\mathrm{d} t}=\frac{1}{W} \cdot \frac{\mathrm{d} W}{\mathrm{~d} t}
$$

(the growth rate relative to the initial weight). The RGRs were then statistically analyzed using analysis of variance. The corresponding weight changes with time were depicted graphically by calculating the backtransformed mean logarithm weight for each time point, then subtracting the initial backtransformed mean logarithm weight, using only earthworms with complete data in the calculation, since RGRs can only be calculated for such earthworms. For earthworm survival at week 9 , a chi-squared test was used to compare mortality of the three earthworm species and to compare BSTI and control treatments (both as "main effect" means).

\section{ACKNOWLEDGEMENTS}

The authors thank Richard Townsend for collection of earthworms, Dave Saville for statistical analysis and Gnanaseela Wadasinghe for growing the tobacco plants. The work was funded by the New Zealand Public Good Science Fund administered by the Foundation for Research, Science and Technology (Contract No. C10X0232).

Received July 24, 2006; accepted August 1st, 2007.

\section{REFERENCES}

Ahl Goy P, Warren G, White J, Privalle L, Fearing P (1995) Interaction of an insect tolerant maize with organisms in the ecosystem. Proceedings of the Key Biosafety Aspects of Genetically Modified Organisms, Blackwell, Berlin, BerlinDahlem, pp 50-53 (cited in Ahmad et al. below)

Ahmad A, Wilde GE, Yan Zhu K (2006) Evaluation of effects of soil containing corn roots or biomass from transgenic corn expressing the coleopteran-specific $\mathrm{Cry} 3 \mathrm{Bb} 1$ protein on earthworms. Environ. Entomol. 35: 976-985
Allsopp PG, Nutt KA, Geijskes RJ, Smith GR, Suasa AW (2000) Transgenic sugarcane with increased resistance to canegrubs. In Allsopp PG, ed, Sugarcane Pest Management in the New Millennium, 4th Sugarcane Entomology Workshop, International Society for Sugar Cane Technology, Khon Kaen, Thailand, pp 63-67

Ashouri A, Michaud D, Cloutier C (2001) Unexpected effects of different potato resistance factors to the Colorado potato beetle (Coleoptera: Chrysomelidae) on the potato aphid (Homoptera: Aphididae). Environ. Entomol. 30: 524-532

Berg MP, Stoffer M, van den Heuvel HH (2004) Feeding guilds in Collembola based on digestive enzymes. Pedobiologia 48: 589-601

Bewley GC, DeVillez EJ (1968) Isolation and characterization of the digestive proteinases in the earthworm Lumbricus terrestris Linneus. Comp. Biochem. Physiol. 25: 1061-1066

Bitzer RJ, Buckelew LD, Pedigo LP (2002) Effects of transgenic herbicide-resistant soybean varieties and systems on surface-active springtails (Entognatha: Collembola). Environ. Entomol. 31: 449-461

Burgess EPJ, Main CA, Stevens PS, Christeller JT, Gatehouse AMR, Laing WA (1994) Effects of protease inhibitor concentration and combinations on the survival, growth and gut enzyme activities of the black field cricket, Teleogryllus commodus. J. Insect Physiol. 40: 803-811

Burgess EPJ, Lövei GL, Malone LA, Nielsen IW, Gatehouse HS, Christeller JT (2002) Prey-mediated effects of the protease inhibitor aprotinin on the predatory carabid beetle Nebria brevicollis. J. Insect Physiol. 48: 1093-1101

Chari MS, Rao RSN, Prabhu SR (1992) Bio-efficacy of nicotine sulphate against pests of different crops. Tobacco Res. 18: 113-116

Christeller JT, Burgess EPJ, Mett V, Gatehouse HS, Markwick NP, Murray C, Malone LA, Wright MA, Philip BA, Watt D, Gatehouse LN, Lövei GL, Shannon AL, Phung MM, Watson LM, Laing WA (2002) The expression of a mammalian proteinase inhibitor, bovine spleen trypsin inhibitor in tobacco and its effects on Helicoverpa armigera larvae. Transgenic Res. 11: 161-173

Christeller JT, Malone LM, Todd JH, Marshall RM, Burgess EPJ, Philip BA (2005) Distribution and residual activity of two insecticidal proteins, avidin and aprotinin, expressed in transgenic tobacco plants, in the bodies and frass of Spodoptera litura larvae following feeding. J. Insect Physiol. 51: 1117-1126

Christeller JT, Markwick NP, Poulton J, O'Callaghan M (2006) Binding of an insecticidal transgene protein product to soil: Biological activity of soil-bound avidin and the effects of time and microbial activity. Soil Biol. Biochem. 38: 20432052

Clark BW, Coats JR (2006) Subacute effects of Cry 1Ab Bt corn litter on the earthworm Eisenia fetida and the springtail Folsomia candida. Environ. Entomol. 35: 1121-1129

Cowgill SE, Bardgett RD, Kiezebrink DT, Atkinson HJ (2002) The effect of transgenic nematode resistance on nontarget organisms in the potato rhizosphere. J. Appl. Ecol. 39: 915-923 
de Leo F, Bonade-Bottino M, Ceci LR, Gallerani RM, Jouanin L (2001) Effects of a mustard trypsin inhibitor expressed in different plants on three lepidopteran pests. Insect Biochem. Mol. Biol. 31: 593-602

Delledonne M, Allegro G, Belenghi B, Balestrazzi A, Picco F, Levine A, Zelasco S, Calligari P, Confalonieri M (2001) Transformation of white poplar (Populus alba L.) with a novel Arabidopsis thaliana cysteine proteinase inhibitor and analysis of insect pest resistance. Molec. Breed. 7: 35-42

Donegan K, Seidler R, Fieland V, Schaller D, Palm C, Ganio L, Cardwell D, Steinberger Y (1997) Decomposition of genetically engineered tobacco under field conditions: persistence of the proteinase inhibitor I product and effects on soil microbial respiration and protozoa, nematode and microarthropod populations. J. Appl. Ecol. 34: 767-777

El-Gayar F, El-Shazli A, Khafagy S, Watson W (1975) Studies on the alkaloidal contents of Nicotiana rustica var. brasilia, and its insecticidal activity against Culex pipiens L. (Dipt.: Culicidae) and Spodoptera littoralis Boisd. (Lep.: Noctuidae). Z. Angew. Entomol. 78: 49-55

Ferry N, Edwards MG, Gatehouse JA, Gatehouse AMR (2004) Plant-insect interactions: molecular approaches to insect resistance. Curr. Opin. Biotechnol. 15: 155-161

Fioretti E, Iacopino G, Angeletti M, Barra D, Bossa F, Ascoli F (1985) Primary structure and antiproteolytic activity of a Kunitz-type inhibitor from bovine spleen. J. Biol. Chem. 260: 11451-11455

Flores S, Saxena D, Stotzky G (2005) Transgenic Bt plants decompose less in soil than non-Bt plants. Soil Biol. Biochem. 37: $1073-1082$

Fountain MT, Hopkin SP (2005) Folsomia candida (Collembola): a 'standard' soil arthropod. Annu. Rev. Entomol. 50: 201-222

Gatehouse JA, Gatehouse AMR, Brown DP (2000) Control of phytophagous insect pests using serine proteinase inhibitors. In Michaud D, ed, Recombinant Protease Inhibitors in Plants, Landes Bioscience, Eurekah.com, Texas, USA, pp 9-26

Hopkins DW, Gregorich EG (2003) Detection and decay of the $\mathrm{Bt}$ endotoxin in soil from a field trial with genetically modified maize. Eur. J. Soil Sci. 54: 793-800

James C (2005) Global Status of Commercialized Transgenic Crops: 2005. The International Service for the Acquisition of Agri-biotech Applications (ISAAA), Ithaca, NY. http://www.isaaa.org/kc/bin/briefs34/es/index.htm

Kula H, Larink O (1998) Tests on the earthworms Eisenia fetida and Aporrectodea caliginosa. In Lokke H, van Gestel CAM, eds, Handbook of Soil Invertebrate Toxicity Tests, John Wiley and Sons, Chichester, UK, pp 95-112

Laskowski MJ, Kato I (1980) Protein inhibitors of proteinases. Ann. Rev. Biochem. 49: 593-626

Malone LA, Todd JH, Burgess EPJ, Christeller JT (2004) Development of hypopharyngeal glands in adult honey bees fed with a Bt toxin, a biotin-binding protein and a protease inhibitor. Apidologie 35: 655-664
Markwick NP, Laing WA, Christeller JT, McHenry JZ, Newton MR (1998) Overproduction of digestive enzymes compensates for inhibitory effects of protease and a-amylase inhibitors fed to three species of leafrollers (Lepidoptera: Tortricidae). J. Econ. Entomol. 91: 1265-1276

Rebek EJ, Hogg DB, Young DK (2002) Effect of four cropping systems on the abundance and diversity of epedaphic springtails (Hexapoda: Parainsecta: Collembola) in southern Wisconsin. Environ. Entomol. 31: 37-46

Romeis J, Battini M, Bigler F (2003) Transgenic wheat with enhanced fungal resistance causes no effects on Folsomia candida (Collembola: Isotomidae). Pedobiologia 47: 141-147

Saxena D, Stotzky G (2001a) Bacillus thuringiensis (Bt) toxin released from root exudates and biomass of $\mathrm{Bt}$ corn has no apparent effect on earthworms, nematodes, protozoa, bacteria and fungi in soil. Soil Biol. Biochem. 33: 1225-1230

Saxena D, Stotzky G (2001b) Bt corn has a higher lignin content than non-Bt corn. Am. J. Bot. 88: 1704-1706

Snider R (1973) Laboratory observations on the biology of Folsomia candida (Willem) (Collembola: Isotomidae). Rev. Ecol. Biol. Sol 10: 103-124

Stam EM, van de Leemkule MA, Ernsting G (1996) Tradeoffs in the life history and energy budget of the parthenogenetic collembolan Folsomia candida (Willem). Oecologia 107: 283-292

Terra WR, Ferreira C (1994) Insect digestive enzymes: properties, compartmentalization and function. Comp. Biochem. Physiol. 109B: 1-62

van Amelsvoort PAM, Usher MB (1989) Egg production related to food quality in Folsomia candida (Collembola: Isotomidae): effects on life history strategies. Pedobiologia 33: $61-66$

Vercesi ML, Krogh PH, Holmstrup M (2006) Can Bacillus thuringiensis $(B t)$ corn residues and Bt-corn plants affect life-history traits in the earthworm Aporrectodea caliginosa? Appl. Soil Ecol. 32: 180-187

Vincent JP, Lazdunski M (1972) Trypsin-pancreatic trypsin inhibitor association. Dynamics of the interaction and role of disulfide bridges. Biochem. 11: 2967-2977

Voisey CR, Dudas B, Biggs R, Burgess EPJ, Wigley PJ, McGregor PG, Lough TJ, Beck DL, Forster RLS, White DWR, Spangenberg G (2001) Transgenic pest and disease resistant white clover plants. In Spangenberg G, ed, Molecular Breeding of Forage Crops. Developments in Plant Breeding, Kluwer Academic Publishers, London, UK, pp 239-250

Yu L, Berry RE, Croft BA (1997) Effects of Bacillus thuringienesis toxins in transgenic cotton and potato on Folsomia candida (Collembola: Isotomidae) and Oppia nitens (Acari: Orbatidae). J. Econ. Entomol. 90: 113-118

Zwahlen C, Hilbeck A, Howald R, Nentwig W (2003) Effects of transgenic Bt corn litter on the earthworm Lumbricus terrestris. Molec. Ecol. 12: 1077-1086 